\title{
Evaluation of Mortality and Morbidity in Off- pump Coronary Artery Bypass Grafting Versus Coronary Artery Bypass Grafting with Cardiopulmonary Bypass in Diabetic Patient Study at NICVD.
}

\author{
Al Masum Ziaul Haque, Nasir Uddin Ahmed, M I Zulkarnine, Saleh Ahmed \\ Department of Cardiac Surgery, NICVD, Dhaka
}

Keywords:
IHD, CABG,
Cardiopulmonary
bypass, Diabetes
mellitus.

Abstract:

Background: Cardiopulmonary bypass is associated with increased incidence of hyperglycemia. Many studies have shown that diabetes is associated with increased morbidity and mortality in coronary artery bypass (CABG) surgery. We reviewed the outcome of on-pump versus off pump $C A B G$ in diabetic patients.

Methods- 80 Adult diabetic patients undergoing isolated CABG both on-pump and OPCAB were divided into 2 groups - 40 patients in each group. To evaluate both preoperative, perioperative and postoperative out come and to compare their in hospital outcome mortality and morbidity.

Results: Diabetic patients undergoing coronary artery bypass grafting without cardiopulmonary bypass had fewer complications, including neurological dysfunction $(7.5 \%$ vs. $10.0 \%, p=0.1)$, and reduced incidence of prolonged ventilation $(7.5 \%$ vs. $12.5 \%, p=0.709)$, atrial fibrillation $(15.0 \%$ vs. $20.0 \%, p=0.002$ ), and renal dysfunction (10.0\% vs. $17.5 \%, p=0.556)$. In postoperative period, $70 \%$ patients in OPCAB group did not experience any cardiac events whereas $30 \%$ patients developed myocardial infarction, $5 \%$ had cardiac arrest and $7.5 \%$ had low output syndrome. . In on pump group $65 \%$ patients had no cardiac events whereas $35 \%$ patients developed one or more cardiac events. Of them $20 \%$ patients developed atrial fibrillation, $2.5 \%$ developed myocardial infarction, $2.5 \%$ develop cardiac arrest and 10\% had low output syndrome. 2.5\% patient developed both atrial fibrillation and low output.

Conclusion: Diabetic patients undergoing CABG without cardiopulmonary bypass compared with those having coronary artery bypass grafting with cardiopulmonary bypass had higher mean predicted mortality and morbidity.

(Cardiovasc. j. 2020; 13(1): 12-18)

\section{Introduction:}

Diabetes mellitus (DM) is an established risk factor for the development of coronary artery disease. Coronary artery disease is not only more prevalent in diabetic patients compared with nondiabetic patients, but also tends to be more extensive, involving multiple vessels, and rapidly progressive 5 R.M Jacoby and R.W Nesto, Acute myocardial infarction in the diabetic patient pathophysiology, clinical course and prognosis, J Am Coll Cardiol 20 (1992), pp. 726-744.. Accordingly, diabetic patients represent a large proportion of patients requiring myocardial revascularization. Unfortunately, diabetes is also a significant risk factor for adverse early and late outcomes after surgical revascularization. ${ }^{1}$ Symptoms of hyperglycemia and a random plasma glucose $>200$ $\mathrm{mg} / \mathrm{dl}(11.1 \mathrm{mmol} / \mathrm{L})$ defines DM. ${ }^{2}$ Patients with

\footnotetext{
๑ 2020 authors; licensed and published by International Society of Cardiovascular Ultrasound, Bangladesh Chapter and Bangladesh Society of Geriatric Cardiology. This is an Open Access article distributed under the terms of the CC BY NC 4.0 (https://creativecommons.org/licenses/by-nc/4.0)
}

Address of correspondence: Dr. Al Masum Ziaul Haque, Department of Cardiac Surgery, National Institute of Cardiovascular Diseases, Dhaka, Bangladesh. Email- amzcts@gmail.com 
diabetes mellitus who undergo CABG surgery have increased perioperative mortality and morbidity, significantly reduced long-term survival, and less freedom from recurrent episodes of angina. ${ }^{3-6}$

During CPB hyperglycemia in preexisting diabetes mellitus is exacerbated by hormonal stress response to surgery, impaired insulin production and peripheral insulin resistance resulting from elevated levels of the counteregulatory hormones, including cortisol, epinephrine and growth hormone. Even in non - diabetes, the same mechanisms lead to hyperglycemia. ${ }^{6,7}$

Hyperglycemia (DM) interferes with monocyte and neutrophil function, affects endothelial function and induces the expression of pro-inflammatory cytokines. These events might be responsible for a directly negative effect of hyperglycemia, including the facilitation of wound infection or sepsis with or without multiorgan failure indirectly, hyperglycemia might be a surrogate parameter for insulin resistance. ${ }^{8}$

Lazar et al. has shown that maintaining serum glucose $\leq 200 \mathrm{mg} / \mathrm{dL}$ using a modified GIK solution in diabetic patients decreases perioperative morbidity, enhances sur-vival, and diminishes recurrent ischemic events. ${ }^{9}$ A $20 \mathrm{mg} / \mathrm{dl}$ increase in blood glucose level was associated with more than $30 \%$ increase in adverse effects. ${ }^{10}$ Patients with diabetes mellitus who undergo CABG sur-gery have increased perioperative mortality and morbid-ity, significantly reduced long-term survival, and less free-dom from recurrent episodes of angina. The poorer outcomes in these patients have been attributed to a higher incidence of left ventricular dysfunction, altered endothelial function, more diffuse coronary disease, abnormal fibrino-lytic and platelet function, and impaired glucose utilization. ${ }^{10-12}$

Every operation result in hyperglycemia due to the stress response associated with them. CPB is associated with increased incidence of hyperglycemia. Many studies have shown that diabetes is associated with increased morbidity and mortality in CABG surgery. We reviewed CABG experience to determine the impact of cardiopulmonary bypass in diabetic patients undergoing CABG surgery.

\section{Methods:}

This is a prospective, non-randomized, observational study conducted from January 2008 to December 2010 in the Department of Cardiac Surgery of National institute of cardiovascular diseases, Dhaka. 80 Adult diabetic patients undergoing isolated $\mathrm{CABG}$ were divided into 2 groups - 40 patients in each group, Off-pump CABG with diabetes $(n=40)$ group $-A$, On -pump CABG with diabetes $(n=40)$ group-B. Diabetic patients undergoing CABG having left ventricular $\mathrm{EF}<35 \%$ were excluded. We followed the treatment protocol for diabetic patients. In diabetic patients taking oral hypoglycemic agents discontinued after admission into the hospital and converted into insulin (subcutaneous). Those diabetic patients taking insulin was also continued and adjusted insulin dose after measuring blood glucose level. Their dose was held at the morning before surgery. Following protocol was followed-

If blood glucose level is

$>10 \mathrm{mmol} / \mathrm{L}$-Start with a bolus of $2 \mathrm{U}$, followed by insulin infusion at 2 units/hour.

Repeat blood glucose measurement every 30 minutes.

$>10 \mathrm{mmol} / \mathrm{L}$ - Increase infusion by $2 \mathrm{U} / \mathrm{h}$.

$>6$ and $<10 \mathrm{mmol} /$. - Maintain current infusion rate $<6.0 \mathrm{mmol} / \mathrm{L}=$ Stop insulin infusion

$<4.0 \mathrm{mmol} / \mathrm{L}$ - Stop insulin infusion; administer $25 \mathrm{~mL}$ of $50 \%$ dextrose

Maximum insulin infusion, $20 \mathrm{U} / \mathrm{h}$.

Postoperative hyperglycemia protocol for CABG surgery patients:

Goal was to maintain blood sugar (BS) between 110 $\mathrm{mg} / \mathrm{dl}$ and $180 \mathrm{mg} / \mathrm{dL}$ after surgery. Check glucometer Blood Sugar 2 hourly; increase to hourly during rapidly changing conditions and decrease to 4 hourly if no changes in insulin drip rate for $6 \mathrm{~h}$ and serum Blood Sugar $<180 \mathrm{mg} / \mathrm{dl}$ on 3 consecutive measurements. Correlate glucometer Blood Sugar to serum Blood Sugar daily. Serum potassium was maintained $>4 \mathrm{mEq} / \mathrm{L}$.

Measures of variables: Age (years), Sex, Dyslipidemia, Hypertension, Smoking. Oral 
hypoglycemic agents, insulin use, Pre-operative serum glucose level, Left ventricular EF, Coronary artery pathology, Per-operative measures Serum glucose level, Total operative time, Number of graft, total grafting time. Post-operative out comes- Ventilation time in hours (prolonged ventilation time $>48$ (hours), ICU stay (hours), CVD ( Neurological dysfunction), reoperation for bleeding, renal impairment, wound infection, myocardial infraction, cardiac arrest, LOS (Low output syndrome), atrial fibrillation, length of hospital stay, mortality (operative and postoperative), immediate post- operative blood glucose measurement. Follow up at one month was done by clinical evaluation, Echocardiographic evaluation, ECG, Blood sugar evaluation.

\section{Results:}

Age were $55.25 \pm 5.1$ years and $54.75 \pm 5.2$ years respectively $(\mathrm{p}=0.510)$. In this study among 40 patients in off-pump CABG $3(7.5 \%)$ patients were female and in on-pump CABG 1(2.5\%) patients were female ( $p>0.05)$.

\section{Table-I}

Preoperative risk factors among the study population $(n=80)$.

\begin{tabular}{lccc}
\hline Risk Factors & $\begin{array}{c}\text { Off-pump } \\
\text { CABG } \\
\text { freq. } \%)\end{array}$ & $\begin{array}{c}\text { On-pump } \\
\text { CABG } \\
\text { freq. (\%) }\end{array}$ & p value \\
\hline Smoking & $22(55 \%)$ & $21(51.5 \%)$ & 0.792 \\
Hypertension & $30(75 \%)$ & $27(67.5 \%)$ & 0.785 \\
Hyperlipidemia & $29(72.5 \%)$ & $26(63 \%)$ & 0.176 \\
\hline
\end{tabular}

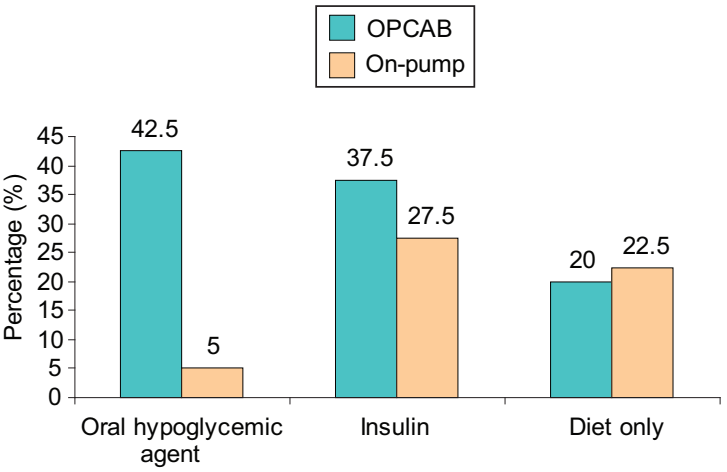

Fig-1: Antidiabetic therapy of both groups.

\section{Table-II}

Preoperative random blood glucose level

\begin{tabular}{lcc}
\hline Group & Mean $( \pm \mathrm{SD})(\mathrm{mmol} / \mathrm{L})$ & $\mathrm{p}$ value \\
\hline Group A (OPCAB) & $8.86( \pm 1.56)$ & 0.684 \\
Group B (On -pump) & $8.72( \pm 1.50)$ & \\
\hline
\end{tabular}

Number of coronary arteries involved were compare between the groups. In Off-pump group, $42.5 \%$ patients had double coronary artery involvements and rest $50 \%$ and $7.5 \%$ had triple coronary artery and Single coronary involvements. In On-pump group, double and triple vessel coronary artery involvements were found in $47.5 \%$ and $52.5 \%$ patients respectively. The LM involvements both groups were $15 \%$ and $17.5 \%$ (p value $>$.05).

Number in parenthesis indicate percentage. $\mathrm{P}$ value $>.05$, but number of incidences differ in both group Major post-operative Complications.

In postoperative period, 28 (70\%) patients in OPCAB group did not experience any cardiac events whereas $12(30 \%)$ patients developed different cardiac events. Among them AF were 6 (15\%), myocardial infarction 1 (2.5\%), 2 (5\%) had cardiac arrest and $3(7.5 \%)$ had low output syndrome.

In On-pump group, 26 (65\%) had no post-operative cardiac events. whereas 14 (35\%) patients developed one or more cardiac events. Of them 8 (20\%) patients developed atrial fibrillation, $1(2.5 \%)$ developed myocardial infarction, 1(2.5\%) develop cardiac arrest and $4(10 \%)$ had low output syndrome. $1(2.5 \%)$ patient developed both atrial fibrillation and low output in postoperative period.

The mortality was found 2(5\%) in Off-pump group one due to per-operative ventricular fibrillation and one postoperative LOS, 3(7.5\%) in On-pump, one due to failure to wean from cardiopulmonary bypass one due to low output syndrome and one due to postoperative cardiac arrest. A total of 5 patients died out of eighty CABG in this series, mortality percentage being $6.66 \%$. difference was not be stated as statically significant $\mathrm{p}=.608(\mathrm{P}>0.05)$. The mean difference of $\mathrm{LVEF}$ from pre-operative period to Post operatively after 1 months between Off-pump was 8.78 \pm 8.0 (\%) and On-pump CABG was $7.78 \pm 3.4$ (\%). The improvement of LVEF between Off-pump and Onpump was not statistically insignificant $(\mathrm{p}>0.05)$ in unpaired students' t-test. 
Table-III

ICU events among the study population $(n=80)$.

\begin{tabular}{lccc}
\hline Findings & Off-pump & On-pump & \\
& CABG (Mean \pm SD) & CABG (Mean \pm SD) & p-value \\
\hline Period of mechanical ventilation (hours) & $7.5 \pm 2.7$ & $12.5 \pm 3.7$ & 0.001 \\
ICU Stay (hours) & $30.1 \pm 6.6$ & $36.6 \pm 7.6$ & 0.002 \\
Total post- operative hospital stays (days) & $6.3 \pm 0.8$ & $8.7 \pm 2.1$ & 0.001 \\
\hline
\end{tabular}

$\mathrm{S}=$ Significance; $\mathrm{P}$-value $<0.05$ was considered significant. (Student $\mathrm{t}$ Test),

Table-IV

Postoperative events among the study population $(n=80)$.

\begin{tabular}{lccc}
\hline Major post-operative Complications & $\begin{array}{c}\text { Off-pump } \\
\text { CABG freq. (\%) } \\
(\mathrm{n}=40)\end{array}$ & $\begin{array}{c}\text { On-pump } \\
\text { CABG freq. }(\%) \\
(\mathrm{n}=40)\end{array}$ & p value \\
\hline Neurological dysfunction & $1(2.5 \%)$ & $3(7.5 \%)$ & 0.608 \\
Renal dysfunction & $2(5 \%)$ & $3(7.5 \%)$ & 0.055 \\
Prolonged ventilation $>48$ hours & $3(7.5 \%)$ & $5(12.5 \%)$ & 0.709 \\
Sternal wound infection & $2(5 \%)$ & $2(5 \%)$ & 0.050 \\
Requirements-operation for bleeding & $1(2.5 \%)$ & $3(7.5 \%)$ & 0.608 \\
\hline
\end{tabular}

Table-V

Showing types of postoperative cardiac events.

\begin{tabular}{|c|c|c|c|c|c|}
\hline & & & \multicolumn{2}{|c|}{ Group } & \multirow[t]{2}{*}{$\mathrm{p}$ value } \\
\hline & & & OPCAB & On-pump & \\
\hline \multirow[t]{7}{*}{ Cardiac events } & Absent & No cardiac event & $28(70)$ & $26(65)$ & 0.633 \\
\hline & Present & Atrial fibrillation & $6(15)$ & $8(20)$ & 0.556 \\
\hline & & Myocardial infarction & $1(2.5)$ & $1(2.5)$ & 1.00 \\
\hline & & cardiac arrest & $2(5)$ & $1(2.5)$ & 1.00 \\
\hline & & Low output syndrome & $3(7.5)$ & $4(10)$ & 1.00 \\
\hline & & Myocardial infarction + Low output syndrome & & 0 & - \\
\hline & & Atrial fibrillation + Low output syndrome & 0 & $1(2.5)$ & - \\
\hline Total & $40(100)$ & $40(100)$ & & & \\
\hline
\end{tabular}

Number in parenthesis indicate percentage. $\mathrm{p}$ value $>.05$, but number of incidences differ in both groups.

\section{Discussion:}

NICVD is one of the best referral hospitals for CABG operation. The first CABG (on-pump) surgery was done at NICVD, Bangladesh, in 1985. OPCAB surgery is being performed since 1997 in NICVD then subsequently in other cardiac centers in Bangladesh.

The mean age was 67 years for the off pump and 68 years for the on-pump groups in the study of Yokoyama et al. ${ }^{13} \mathrm{~A}$ study by Calafiore et al. ${ }^{14}$ had a mean age of $64.4 \pm 9.6$ years for OPCAB patient and $63.3 \pm 9.7$ years for on pump CABG patients. This study mean ages of off-pump and On-pump group of patients were $54.75 \pm 5.2,55.25$ years respectively. In this study among 40 patients in off-pump CABG $3(7.5 \%)$ patients were female and in on-pump CABG 1(2.5\%) patients were female.

In a study by Calafiore et al. ${ }^{14}$ found 2 vessel disease and 3 vessel disease were $36.8 \%$ and $63.2 \%$ in OPCAB and $23.9 \%$ and $76.1 \%$ in on pump CABG group respectively. Chamberlain et al. ${ }^{15}$ reported double vessel affected and 3 vessels affected were $28.2 \%$ and $60.4 \%$ in off pump and $18.9 \%$ and $77.3 \%$ in on pump CABG group respectively. In the observation of Hernandez et al. ${ }^{16} 2$ diseased vessels were $35.6 \%$ and $35.3 \%$ and 3 diseased vessels were $39 \%$ and $44.7 \%$.in OPCAB and CCAB 
respectively. Our study, in off-pump group $42.5 \%$ cases had double vessel disease and 50\% case had triple and $7.5 \%$ had single vessel disease. In Onpump group, $47.5 \%$ patients had double vessel disease and $52.5 \%$ patients had triple vessel disease. Hernandez et al study was near to similar our study

In a study of Arom et al. ${ }^{17}$ smoker was $22 \%$ and $18.8 \%$ in off-pump and on-pump group, diabetes was $33.3 \%$ in off-pump and $33.8 \%$ in on-pump. Hypertension was $66.7 \%$ and $53.4 \%$ in off-pump and on-pump patient.

A study on 1570 high risk patients by Chamberlain et al. ${ }^{15}$ reported hypertension was $60.7 \%$ and $61.9 \%$ in off-pump and on-pump group respectively, hypercholesterolemia $75.2 \%$ and $68.3 \%$ in off-pump and on-pump group and smoker was $74.7 \%$ and $77 \%$ in off-pump and on-pump patient respectively. In this study the pre-operative risk factors smoking, hypertension and Hyperlipidemia were the predominance risk factor in both groups (55\% vs. $51.5 \%$ and $75.7 \%$ vs. $67 \%$ and $72.5 \%$ vs. 635 in off-pump vs. on-pump CABG respectively. Chamberlain et al. ${ }^{15}$ study was similar to our study, but no significant difference exists in between groups. Both groups were almost comparable regarding other risk factors.

The length of operation time Mean \pm SD was $213 \pm 56.7$ (min) and 252.1 $\pm 80.8(\mathrm{~min})$ in OPCAB vs. CABG in the study of. Arom et al. ${ }^{17}$ reported that total operation time was $175 \mathrm{~min}$ and $235 \mathrm{~min}$ in off pump and on pump group respectively. In a study by Shennib et al. ${ }^{18}$ observed that total operation time was $192.1 \pm 42.2 \mathrm{~min}$ and $199.8 \pm 42.2$ in off pump and on pump respectively. Czerny et al. ${ }^{19}$ in a study reported duration of operation in OPCAB and CCAB were $178 \pm 49$ min and $254 \pm 64$ min respectively. Compare to our study shows in per-operative finding between groups demonstrates that total operative time in off-pump group (165.3 $\pm 20.9 \mathrm{~min})$ is significantly less than that of on-pump group (205.3 $\pm 48.4 \mathrm{~min})$ in this study, the average number of grafts in off-pump group was $2.9 \pm 0.7$ and in on- pump group $(3.2 \pm 0.8)$ were comparable.

Several post-operative out-come have been compared between groups, In a study by Czerny et al. ${ }^{19}$ reported intubations time (hours) was $4.8 \pm 2.9$ in OPCAB and 17.7 \pm 24.4 in on pump CABG, mean ICU stay (days) was $1.2 \pm 0.3$ day in OPCAB and $2.0 \pm 2.8$ days in on pump, in hospital stay was 13.5 \pm 8.2 in OPCAB and $12.6 \pm 7.3$ in on pump. Shennib et al. ${ }^{18}$ found in a study intubations time (hours) was $16.5 \pm 22.4$ in off pump and $22.2 \pm 32.5$ in on pump, ICU length of stay (hours) was $45.5 \pm 52.2$ in off pump and $57 \pm 67.6$ in on pump, postoperative length of stay (days) was $9.3 \pm 9.2$ in off pump and $11.1 \pm 11.5$ in on pump.

Arom et al. ${ }^{17}$ observed in a study intubations time (hours) was 23.5 (67.7) in off pump and 33.2 (118.6) in on pump, ICU hours mean (SD) was 60.5 (83.9) in off pump and 58 (94.1) in on pump and postoperative hospital stay (days) mean (SD) was 8.2(4.7) in off pump and 7.9 (5.7) in on pump groups. Calafiore et al. ${ }^{14}$ showed in a study ICU stay (hours) was $13.5 \pm 16.6$ in off pump and $16.2 \pm 15.3$ in on pump, in hospital stay (day) $4.2 \pm 2.8$ in off pump and $4.9 \pm 2.7$ in on pump. Boyd et al. (1999) 20 reported ventilation time (hour) was $7.9 \pm 5.2$ in off pump and $16.3 \pm 9.7$ in on pump, ICU stay (hour) $24 \pm 10.9$ in off pump and $36.6 \pm 33.5$ in on pump and hospital stay (days) was $6.3 \pm 1.8$ in OPCAB and $7.7 \pm 3.9$ in on pump groups.

In this study mean (Mean \pm SD) ventilation period in off-pump group was $7.5 \pm 2.7$ hours and that in on-pump group was $12.5 \pm 3.7$ hours. This shows that ventilation time was significantly higher in on-pump group. But this is much lower than that in the series of Shennib et al. ${ }^{18}$ suggesting a trend towards early extubation in our institution

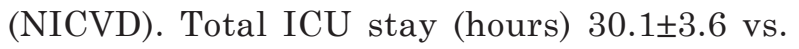
$36.6 \pm 3.7$ and total postoperative stay in hospital averaged $6.3 \pm 0.8$ days in off-pump group of patients and $8.7 \pm 2.1$ days in both group of patients. Thus, the mean period of mechanical ventilation, ICUstay period, total post-operative stay in hospital all were significantly greater in on-pump group as opposed to off-pump group.

All these reflect definite clinical advantage as well as favorable economic outcome associated with offpump group of patients. Yokoyama et al. ${ }^{13}$ in a study on off pump vs. on pump coronary bypass in high risk subgroup showed renal complication was $3.3 \%$ in off pump and $5.4 \%$ in on pump, prolonged ventilation $>72$ hours $3.7 \%$ in off pump and $6.6 \%$ in on pump, neurological complication $3.3 \%$ in off pump and $5 \%$ in on pump CABG. Bull et al. ${ }^{21}$ in a study showed that renal failure was $3 \%$ off pump 
mediastinitis was $5 \%$. In this study on pump CABG patients experienced higher postoperative morbidity than off pump CABG especially renal dysfunction ( $5 \%$ vs. $7.5 \%$ ), prolonged ventilation more than 48 hours $(7.5 \%$ vs. $12.5 \%)$ and deep sternal wound infection ( $5 \%$ vs. $5 \%$ ). Neurological dysfunction was $2.5 \%$ vs. $7.5 \%$. All were similar above mention study.

Ascione et al. ${ }^{22}$ reported in a study mortality was $5.9 \%$ in off pump and $7.9 \%$ in on pump. Ahmed et al. (1988) observed mortality was; $12.5 \%$ in beating heart CABG and $25 \%$ in on pump CABG. Arom et al. ${ }^{15}$ in a study showed operative modality was $4.4 \%$ in off pump and $7.5 \%$ in on pump groups.

In this study 30 days operative mortality was higher in on pump CABG group (7.5\%) than off pump CABG group (5\%) but statistically not significant due to small sample size. But the study was correlate to the other study.

During follow up evaluation improvement is statistically significant. In echocardiographic evaluation in off pump CABG mean difference of LVIDd and LVIDs (51,32 \pm 6.98 vs. $47.47 \pm 7.81$ and $42.02 \pm 6.75$ vs. $36.54 \pm 8.08 \mathrm{~mm}$ ) was statistically significant $(p<0.05)$ in after.1-month postoperative period compare to preoperative period. During the preoperative period LVEF was $45 \pm 8 \%$ and 1 months postoperatively LVEF was $53 \pm 7$ which was significantly higher? compared to per-operative period. In on pump CABG mean difference of LVIDd and LVIDS (49.67 $\pm 4.85 \mathrm{~mm}$ vs. $47.56 \pm 4.78 \mathrm{~mm}$ and $40.22 \pm 4.53 \mathrm{~mm}$ vs. $36.71 \pm 4.13 \mathrm{~mm}$ ) was statistically significant in after 1 month's postoperative period compare to preoperative period. LVEF also improved from $47 \pm 6 \%$ to $54 \pm 5 \%$ after 1 -month postoperative period compare to preoperative period.

The mean difference of LVEF from preoperative period to postoperatively after 1 months between off pump was $8.78 \pm 3.0 \%$ and on pump CABG was $7.78 \pm 3.4 \%$. The improvement of LVEF between off pump and on pump was statistically insignificant $(\mathrm{p}>0.05)$.

Arnese et al. ${ }^{23}$ in a study on prediction of improvement of regional left ventricular function after surgical revascularization reported postoperative improvement occurred in $79 \%$ of severe hypokinetic segment of ventricular wall.
In this study in off pump CABG 95\% patients showed improvement of wall motion abnormality after 1 month postoperatively compared to preoperative period and in on pump CABG $88.9 \%$ patients showed normal wall motion after 3 months postoperatively compared to preoperative period. Both these findings conclusively demonstrated functional improvement and effectiveness of revascularization in both off pump CABG and on pump CABG.

But Mean \pm SD difference between preoperative to postoperative areas was $5.7 \pm 2.1$ in off pump and on pump CABG was $7.8 \pm 8.6$. The Mean \pm SD difference of ejection fraction was $8.5 \pm 2.5$ in off

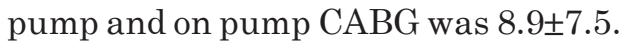

Above these findings indicate functional improvement of treatment group in diabetic CABG patients tending towards a favorable impact on OPCAB CABG outcome in compare to on pump CABG group.

\section{Conclusion}

Off-pump CABG has gained increasing popularity due to its potential to avoid induced myocardial damage by CPB. From this study we concluded that Off-pump CABG provides a significant survival advantage in compare to On-pump CABG in diabetic patients in association with a significant reduction in morbidity. Additional studies including larger number of diabetic patients for prospective randomization is needed to confirm these conclusions.

\section{Study Limitations}

We recognize that there are a number of important limitations with our data and our results. All operations were not performed by the same surgeon and sample size was small.

\section{Conflict of Interest - None.}

\section{Acknowledgement}

We acknowledge the contribution of Prof. Khawaja Nasiruddin Mahmood, Head of the Department, Department of Cardiovascular Surgery, National Institute of Cardiovascular Diseases, Dhaka; Dr Mohammed Ullah Firoze - Assistant Professor, Cardiology. NICVD, Faculties of the Department of Cardiovascular Surgery, NICVD and Department of Anaesthesia, NICVD. 


\section{References}

1. Cohen Y, Raz I, Merin G, et al. Comparison of factors associated with 30-day mortality after coronary artery bypass grafting in patients with versus without diabetes mellitus. Am J Cardiol 1998; 81: 7-11.

2. ADA (American diabetes association). Standards of medical care in diabetes, Diabetes Care 2009; 32 (supplement 1).

3. Krolewski, AJ, Kosinski EJ and Warram JH, et al. Magnitude and determinants of coronary artery disease in juvenile-onset, insulin-dependent diabetes mellitus, Am J Cardiol 1987; 750-755.

4. Saleh A, Alimuzzaman M, Ahmed NU, Sabur SAMA. Influence of diabetes mellitus on early outcome after CABG (MS Thesis). Dhaka. University of Dhaka. July 2002.

5. Tarik KM, Alimuzzaman M, Adhikary AB, Sabur SAMA. Influence of continues $\mathrm{I} / \mathrm{V}$ insulin infution on wound infection after CABG in diabetic PT (MS Thesis). Dhaka. University of Dhaka. Jan 2004; 52.

6. Bojar RM. Manual of peri-operative care in adult cardiac surgery. 4th edition. Massachusetts, USA: Blackwell publishing, 2005: 497.

7. Furmary AP, Zerr KJ, Grunkemeier GL, et al. Continuous intravenous insulin infusion reduces the incidence of deep sternal wound infection in diabetic patients after cardiac surgical procedures. Ann Thorac Surg 1999; 67: 352-362.

8. Vanden BG, Wouters P, Weekers F, Verwaest C, Bruyninck XF, Schetz. M'Intensive insulin therapy in critically ill patients. N Engl J Med 2001; 345: 13591367.

9. Lazar HL, Chipkin SR, Fitzgerald CA, Bao Y, Cabral H, Apstein CS. Tight glycemic control in diabetic coronary artery bypass graft patients improves perioperative outcomes and decreases recurrent ischemic events. Circulation 2004; 109:1497-1502.

10. Gandhi GY, Nuftall GA, Abel MD, Mullany CJ, Schaff $\mathrm{HV}$, Williams BA, et al. Intra-operative hyperglycemia and peri-operative outcomes in cardiac surgery patients. Mayo Clin Proc 2005; 80(7): 862-866.

11. Furnary AP, Gao G, Grunkemeier GL, Wu Y, Zerr KJ, Bookin SO, et al. Continuous insulin infusion reduces mortality in patients with diabetes undergoing coronary artery bypass grafting. J Thorac Cardiovasc Surg 2003; 125 (5): 1007-1028.

12. Lazar HL, Chipkin SR, Fitzgerald CA, Bao Y, Cabral H, Apstein CS. Tight glycemic control in diabetic coronary artery bypass graft patients improves perioperative outcomes and decreases recurrent ischemic events. Circulation 2004; 109: 1497-1502.
13. Yokoyama T, Baumgartner FJ, Gheissare A, Capouya ER, Panaghiotides GP, Declusin RJ. Off pump versus on pump coronary bypass in high risk factors subgroups. Ann Thorac Surg 2000; 70: 1546-1550.

14. Calafiore AM, DiMauro M, Contini M, Giammarco GD. Myocardial revascularization with and without cardiopulmonary bypass in multivessel diseases: impact of the strategy on early outcome. Ann Thorac Surg 2001; 72: 456-463.

15. Chamberlain MH, Ascione R, Reeves BC, Angelini GD. Evaluation of the effectiveness of off pump coronary artery bypass grafting in high risk patients; an observational study. Ann Thorac Surg 2002; 72: 18661873.

16. Hernandez F, Cohn W, Baribeau YR, Tryzelaar JF, Charlessworth DC, Clough RA, et al. In-hospital outcomes of off-pump versus on-pump coronary artery bypass procedures: a multicenter experience. Ann Thorac Surg 2001; 72: 1528-1534.

17. Arom KV, Flavin TF, Emery RW, Kshettry VR, Janey PA, Peterson RJ. Safety and efficacy of off-pump coronary artery bypass grafting. Ann Thorac Surg 2000; 69: 704-710.

18. Shennib H, Endo M, Benhamed O, Morin JF. Surgical revascularizationin patients with poor left ventricular function on or off pump. Ann Thorac Surg 2002; 74:13441347.

19. Czerny M, Baumar H, Kilo J, Zukerman A, Girubnofer G, Chevtchik O, et al. Complete revascularization of coronary artery bypass grafting with and without cardiopulmonary bypass. Ann Thorac Surg 2001; 71: 165-169.

20. Boyed WD, Desai ND, Rizzo DF, Novick DR, Mckenzie JN, Menkis AH. Off pump surgery decreases postoperative complication and resource utilization in the elderly. Ann Thorac Surg 1999; 68:1490-1493.

21. Bull DA, Neumayer LA, Stringham JC, Meldrum P, Affleeck DG, Karwande SV. Coronary artery bypass grafting with cardiopulmonary bypass versus off pump cardiopulmonary bypass grafting; does eliminating the pump reduce morbidity and cost? Ann Thorac Surg 2001; 71:170-175.

22. Ascino R, Anglini GD. OPCAB surgery a voyage of discovery back to the future. Eur Heart $J$ 2003; 24: 121124.

23. Arnese M, Cornel JH, Salustri A, Maat APWM, Elhendy A, Reys AEM. et al. Prediction of improvement of regional left ventricular function after surgical revascularization. Circulation 1995; 91: 2748-2752. 